\title{
Martensite crystal structure in Ru-based high temperature shape memory alloys
}

\author{
A. M. Manzoni ${ }^{1.2}$, G. Wallez ${ }^{3.4}$, A. Denquin ${ }^{1}$, F. Prima ${ }^{3}$, R. A. Portier ${ }^{3}$ P. Vermaut $^{3.4}$ \\ ${ }^{1}$ DMSM-ONERA, 29 Avenue de la Division Leclerc, F-92320 Châtillon, France \\ 2 Helmholtz-Zentrum Berlin für Materialien und Energie GmbH, D-14109 Berlin, Germany \\ ${ }^{3}$ Chimie ParisTech, PSL Research University, CNRS, Institut de Recherche de Chimie Paris (IRCP), F- \\ 75005 Paris, France \\ ${ }^{4}$ Sorbonne Universities, UPMC University Paris 06, UFR926, 75005 Paris, France \\ E-mail:anna_manzoni@gmx.net,gilles.wallez@upmc.fr,anne.denquin@onera.fr, \\ frederic.prima@chimie-paristech.fr,richard.portier@chimie-paristech.fr, \\ philippe.vermaut@chimie-paristech.fr
}

\begin{abstract}
$\underline{\text { Abstract }}$
High temperature shape memory alloys $\mathrm{RuNb}$ and RuTa were investigated by X-ray diffraction in order to determine the structure of the low temperature $\beta$ " martensite. Powder X-ray diffraction and Rietveld analysis confirm the monoclinic symmetry and allow a precise determination of the atom positions. The low temperature microstructure is the result of a martensitic transformation from a tetragonal $\beta^{\prime}$ martensite. The analysis of how it is controlled by the space groups of the two phases and by their relative orientation is performed by transmission electron microscopy. A three level twinned microstructure is recognized in the $\beta$ " phase. The investigation at the smallest scale twins reveals the presence of wavy contrast boundaries which are typical for translation interfaces. High resolution transmission electron microscopy images, accompanied by phase contrast imaging analysis, have been used to determine the translation vectors associated to the interfaces. These displacements are the translations of the tetragonal $\beta^{\prime}$ phase which are lost during the transformation. The combination of X-ray diffraction and transmission electron microscopy investigation allows the suggestion of a global distortion mechanism that explains the atomic displacements in the $\beta$ " form.
\end{abstract}

\section{$\underline{\text { Introduction }}$}

Unlike commercial shape memory alloys, which are used in mechanical, medical and biological areas at a relatively low application temperature $\left(<100^{\circ} \mathrm{C}[1]\right), \mathrm{Ru}_{50} \mathrm{Nb}_{50}$ and $\mathrm{Ru}_{50} \mathrm{Ta}_{50}$ high temperature shape memory alloys show transformation temperatures above $600^{\circ} \mathrm{C}$ which makes them potential candidates for application in the automotive and aerospace industry [2]. They are characterized by two successive phase transformations from the cubic austenitic $\beta$ phase over a tetragonal martensitic $\beta^{\prime}$ phase down to a monoclinic martensitic $\beta^{\prime \prime}$ phase $[3,4]$. The final microstructure at room temperature exhibits a complex distribution of variants which are generated by the two successive transformations and which can be described by a three level twinning. In the smallest twin domain, a wavy contrast can be observed [4-8]. The microstructure has been described in detail in [9] and is shown in Figure 1 as a reminder. The schematic view in Figure $1 \mathrm{a}$ and the transmission electron microscopy (TEM) bright field image in Figure $1 \mathrm{~b}$ show the three levels of twins: high scale twins A, middle scale twins B and small scale twins $\mathrm{C}$. The 
twins $\mathrm{A}$ and $\mathrm{C}$ are of type (101) $)_{\mathrm{T}}$ compound (T standing for the tetragonal unit cell). The twins $\mathrm{B}$ are formed along one of the twinning planes $(111)_{\mathrm{M}}=(010)_{\mathrm{T}}(\mathrm{M}$ standing for the monoclinic unit cell). The twinning type in this case is unclear.

A wavy contrast can be seen in the small scale twins $\mathrm{C}$ in the lower part of the image.

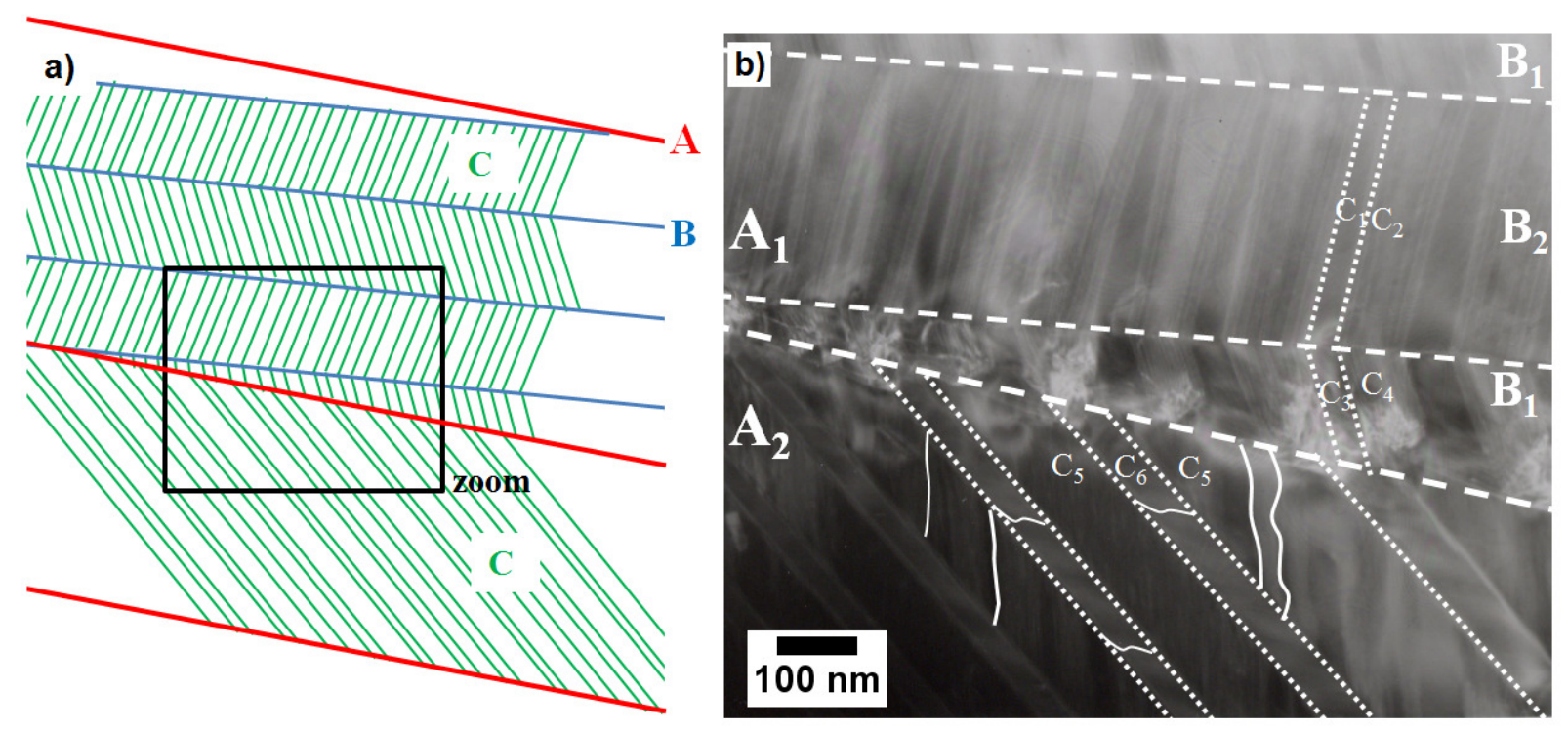

Figure 1: a) A schematic view and b) a TEM bright field image showing the three level twins (highlighted in dashed lines): high scale twins A, middle scale twins B and small scale twins C. A wavy contrast (highlighted in continuous white lines) can be seen in the small scale twins $\mathrm{C}$ in the lower part of the image (image adapted from $[6,9]$ ).

The two high temperature transformations, each of which contributes to the total shape memory effect, make these alloys unique in the family of shape memory alloys $[4,6,10,11]$. While the first transformation from cubic to tetragonal has been widely understood, the second transformation has always been a challenge, as it has not been clear from the beginning whether the structure at room temperature was orthorhombic or monoclinic [8, 12-14]. In 1997 the room temperature structure has been declared monoclinic [8, 13] by Fonda 1997 and a generally acknowledged structure has been proposed [8]. This structure belongs to the $P 2 / \mathrm{m}$ space group and it is shown in Figure 2. The cell consists of $6 \mathrm{Ru}$ atoms and $6 \mathrm{Ta}$ or $\mathrm{Nb}$ atoms. The $\mathrm{Ru}$ atoms are located at the corners of the cell. This supercell is six times bigger than the former tetragonal cell from which it emerges and which it embraces in its centre (marked in red). At first sight, it is not clear why the unit cell of the monoclinic phase needs to be six times bigger than the former tetragonal cell. The small cell, highlighted in red, has a triclinic geometry after the $\beta^{\prime} \rightarrow \beta^{\prime \prime}$ transformation, but it would contain all the symmetry elements that exist in the supercell, if we indeed assumed that its atoms are located in their "ideal" positions, i.e. perfectly aligned and thus forming perfect planes. 


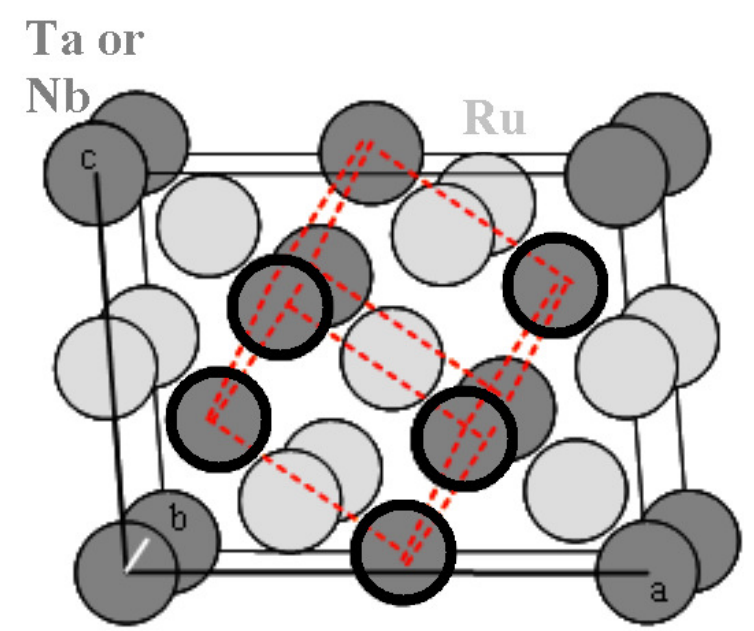

Figure 2: The $P 2 / m$ monoclinic unit cell of $\mathrm{Ru}_{50} \mathrm{Ta}_{50}\left(\right.$ and $\mathrm{Ru}_{50} \mathrm{Nb}_{50}$ ) proposed by Fonda and Vandermeer [8]. Inside the monoclinic cell the former tetragonal cell has been highlighted in red. Five atoms are highlighted with a thick black border: The five vectors linking the origin to each of these highlighted atoms correspond to the five lost translations which are lost during the $\beta^{\prime} \rightarrow \beta^{\prime \prime}$ transformation

While studying these materials, it has become clear that this structure with "ideal" atomic positions is not correct for explaining the experimental observations $[6,7,10]$. One example for the necessity of a supercell is the presence of supplementary peaks in XRD observations and diffraction spots in TEM analysis [6, 7, 10]. Furthermore, Fonda and Jones have described some features which have the appearance of antiphase boundaries or $\delta$ boundaries in RuNb [15] and Fonda and Vandermeer describe the same features in RuTa [8]. The authors attribute these features to the monoclinicity of the materials $[8,15]$. These observations are of great interest in terms of understanding the supercell's properties.

In this work we will focus on a refinement of the description of the monoclinic structure and the explanation of the antiphase boundary like observations.

\section{Experimental}

All elements used for the fabrication of the alloys were of commercial purity. The alloys were made by arc melting technique and remelted several times in order to ensure a sufficient homogeneity. Furthermore, the alloys were homogenized in a vacuum furnace at $1600^{\circ} \mathrm{C}$ for 168 hours.

The samples for transmission electron microscopy (TEM) observations were cut by an electro wire discharge machine and mechanically polished down to a thickness of $\sim 140 \mu \mathrm{m}$. They were then polished electrochemically with an electrolyte containing 20 vol.\% $\mathrm{H}_{2} \mathrm{SO}_{4}$ and 80 vol.\% methanol at a voltage of $20.5 \mathrm{~V}$, a current of $\sim 90 \mathrm{~mA}$ and a temperature of $\sim-40^{\circ} \mathrm{C}$. Specimens for the first general XRD analysis were mechanically ground and polished down to $50 \mathrm{~nm}$ using a OP-S colloidal silica suspension.

The specimen for refining X-ray powder diffraction (XRPD) measurements was ground in a mortar down to a grain size of about $10 \mu \mathrm{m}$. In order to prevent anisotropy in crystallites orientation, a triple volume of water soluble chicory has been added to the powder before the XRPD experiments.

X-ray measurements were two-fold, both made in Bragg-Brentano geometry with $\mathrm{CuK} \alpha$ radiation. First general experiments were made on a Philips PW 1380 diffractometer. For Rietveld analysis, the pattern was recorded in a range of $10 \leq 2 \theta \leq 140^{\circ}$, a stepsize of $0.013^{\circ}$, for 
13 hours at room temperature in a Panalytical X'Pert Pro diffractometer ( $U=45 \mathrm{kV}, \mathrm{I}=40 \mathrm{~mA})$, equipped with a $\mathrm{Ge}$ (111) fore-monochromator.

The Dicvol program [16] was used to determine the cell parameters based on the 15 first diffraction peaks and the alloys' density.

The diffracted intensities were analyzed using FullProf [17] in Le Bail's (profile matching) mode. Then Patterson and Fourier syntheses were applied, which allows locating the atoms. The refinement of the structures was assured by the Rietveld method with FullProf.

The simulation of diffraction patterns and spectra has been made with the CaRIne software [18]. 


\section{$\underline{\text { Results and discussion }}$}

A TEM bright field (BF) observation and the corresponding diffraction pattern of the $\mathrm{Ru}_{50} \mathrm{Ta}_{50}$ equiatomic alloy is shown in Figure 3.

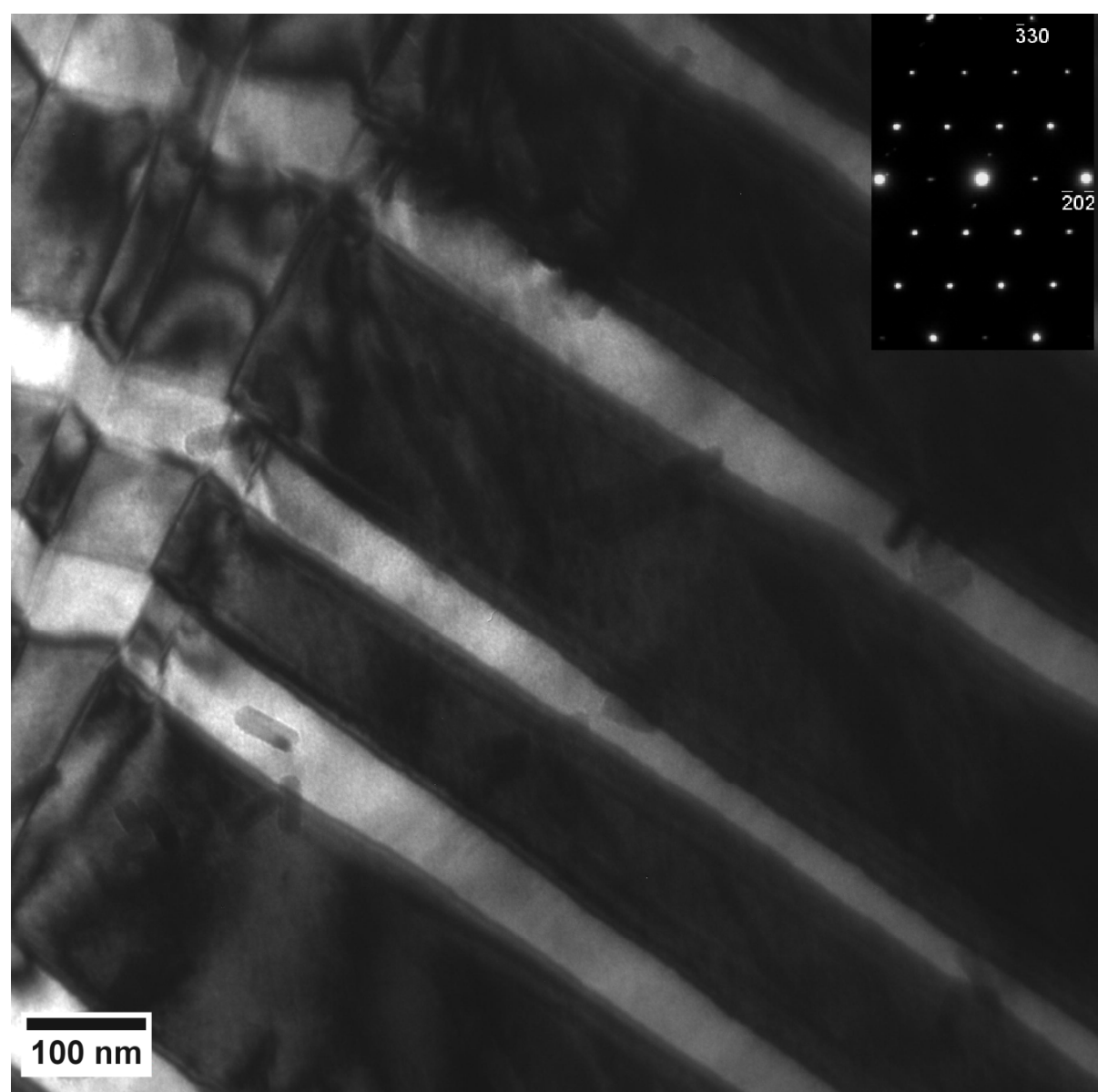

Figure 3: TEM BF and the corresponding SAD taken along the [11 $\overline{1}]$ zone axis in $\mathrm{Ru}_{50} \mathrm{Ta}_{50}$, showing $\mathrm{B}$ and $\mathrm{C}$ scale twins and some small oxide particles on the surface.

The presence of the weaker superstructure reflections imply that the schematic representation of the supercell in Figure 2 is insufficient. If the atoms e.g. in the (101) plane were perfectly aligned, then there would be no superlattice reflections. The additional spots like e.g. $(-1,0,-1)$ only show up if they are shuffled. 


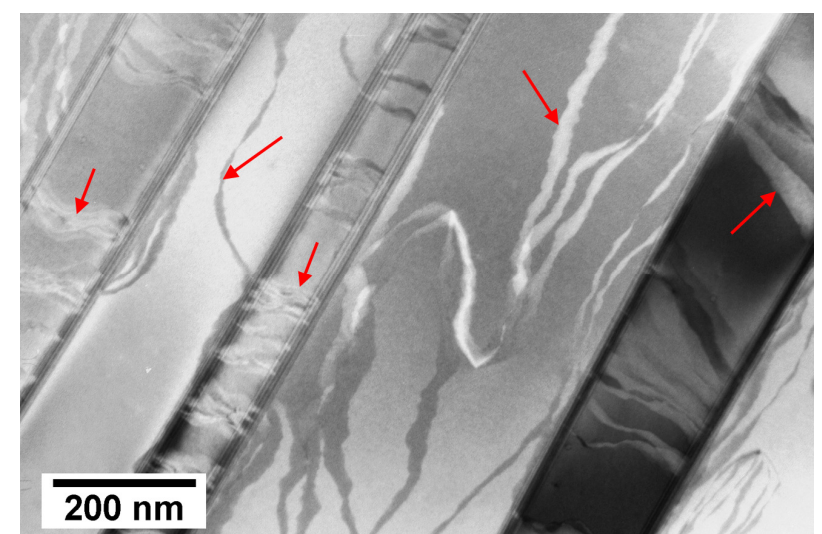

Figure 4: TEM BF image of the smallest scale twins $\mathrm{C}$ of type $(101)_{\mathrm{T}}$ compound in monoclinic $\mathrm{Ru}_{50} \mathrm{Nb}_{50}$ showing wavy translation defects. The red arrows point to the wavy contrasts. The electron beam direction is close to the $[102]_{\mathrm{M}}$ zone axis.

An additional observation has been made during TEM experiments. Figure 4 shows TEM observations of the smallest scale twins $\mathrm{C}$ of type $(101)_{\mathrm{T}}$ compound in $\mathrm{Ru}_{50} \mathrm{Nb}_{50}$. Same background colour can be observed on both sides of the wavy structures inside one same twin $C$. Similar observations have been made in $\mathrm{Ru}_{50} \mathrm{Ta}_{50}$. These features have already been observed by Fonda et al. $[8,15]$ and they have assumed that they are antiphase-like boundaries or $\delta$ boundaries. Both of these assumptions have a weak point, though:

Antiphase boundaries occur in an ordered crystal, which has previously been disordered, as is the Case in $\mathrm{AuCu}$ II. In the disordered crystal, $\mathrm{Cu}$ and $\mathrm{Au}$ atoms are randomly distributed inside the unit cell. In the ordered crystal there are different domains, i.e. those where $\mathrm{Cu}$ has the $(000)$ position and those where Au has the $(000)$ position. These domains are linked by a translation vector. $\delta$ boundaries are a type of twins, which would imply different orientations on both sides of the contrast. This is also not the case here. We will propose a new explanation in this manuscript.

As both alloys behave in a very similar way, in the following, only one of them is described and the other can be considered as equal, except when the difference is clearly pointed out.

The origin of this wavy contrast can be found when observing closely the unit cell of the monoclinic structure, which is displayed in Figure 2. The monoclinic unit cell $(P 2 / \mathrm{m})$ proposed by Fonda and Vandermeer [8] has been taken as a reference. For the sake of demonstrating the incompleteness of an internal triclinic cell, it is first supposed that the atom positions are as summarized in Table 1. This would be the case if the atoms were perfectly aligned, as is the case in the schematic drawing in Figure 2. Inside the monoclinic cell, the former tetragonal cell has been highlighted in red.

\begin{tabular}{cccc}
\hline Atom & $\mathbf{x}$ & $\mathbf{y}$ & $\mathbf{z}$ \\
\hline Ta1 or Nb1 & 0 & 0 & 0 \\
Ta2 or Nb2 & $1 / 2$ & $1 / 2$ & 0 \\
Ta3 or Nb3 & $2 / 3$ & 0 & $1 / 3$ \\
Ta4 or Nb4 & $1 / 6$ & $1 / 2$ & $1 / 3$ \\
Ru1 & 0 & 0 & $1 / 2$ \\
Ru2 & $1 / 2$ & $1 / 2$ & $1 / 2$ \\
Ru3 & $1 / 3$ & 0 & $1 / 6$ \\
Ru4 & $1 / 6$ & $1 / 2$ & $5 / 6$
\end{tabular}

Table 1: Atom position of $\mathrm{Ru}$ and $\mathrm{Ta} / \mathrm{Nb}$ atoms in the $\beta^{\prime \prime}$ cell, derived from their positions in the $\beta^{\prime}$ cell as can be concluded from Figure 2. 
As the monoclinic $\beta^{\prime \prime}$ cell is six times bigger than the tetragonal $\beta^{\prime}$ cell it is clear that the transformation $\beta^{\prime} \rightarrow \beta^{\prime \prime}$ is followed by a loss of some $\beta^{\prime}$ symmetry elements when finally the $\beta^{\prime \prime}$ phase is obtained. A thorough analysis of lost orientation symmetry elements, based on point group symmetry, has been addressed in a recently published work [9]. Another group of lost symmetry elements contains the translations, which are important in this work. The group of $\beta "$ translations is a sub-group of the $\beta^{\prime}$ translations, and it is therefore possible to identify the $\beta^{\prime}$ translations which do not belong to the $\beta^{\prime \prime}$ translations [7]. The increase to a six times bigger unit cell implies six translation variants, which are linked to each other by five translation vectors. They correspond to five translations that are lost during the $\beta^{\prime} \rightarrow \beta^{\prime \prime}$ transformation and they can be visualized by connecting the origin of the unit cell to the atomic positions of these five atoms, which are listed in Table 2 and highlighted in Figure 2 in a thick black line. In the future, these lost translations will be summarized by $\boldsymbol{R}$.

\begin{tabular}{|c|c|}
\hline \multicolumn{2}{|c|}{ Lost translations $(\boldsymbol{R})$} \\
\hline As expressed in $\beta^{\prime}$ & As expressed in $\beta "$ \\
\hline $1 \overline{1} 1$ & $2 / 301 / 3$ \\
\hline $1 \overline{1} 0$ & $1 / 302 / 3$ \\
\hline $0 \overline{1} 0$ & $1 / 61 / 21 / 3$ \\
\hline $1 \overline{2} 1$ & $5 / 61 / 22 / 3$ \\
\hline $0 \overline{1} \overline{1}$ & $1 / 21 / 20$ \\
\hline
\end{tabular}

Table 2: The translations which are lost during the $\beta^{\prime} \rightarrow \beta^{\prime \prime}$ transformation and which correspond to the highlighted atom positions in Figure 2.

Due to the fact that the unit cell of $\beta "$ is large, which leads to a small spacing in the reciprocal lattice, and the small thickness of the twin plates, extinction contrast or Large Angle Convergent Beam Electron Diffraction techniques is a bad choice for the determination of the translation vectors. Thus, in order to obtain more accurate information about the translation contrast, TEM high resolution observations would be a better choice. Furthermore, as the observations in direct space are difficult because of a low signal-to-noise ratio, an analysis of the local phase has been chosen. This way the translation is transformed into a phase change, whose determination is more accurate [19].

Figure 5a shows a TEM BF which highlights the region (red box) where high resolution TEM (HRTEM) is performed along with a phase analysis observations on a translation wall along the $[20 \overline{1}]_{M}$ direction. This zone axis has been chosen because the translation walls are perpendicular to the surface and because it allows the visualization of the stacking of the $(010)_{\mathrm{M}}$ and $(102)_{\mathrm{M}}$ planes. No contrast related to any strain field can be observed in this image.

Figure $5 \mathrm{~b}$ shows the HRTEM image and Figure $5 \mathrm{~b}$ the corresponding power spectrum along with two highlighted spots, belonging to $(010)_{\mathrm{M}}$ and (102) $)_{\mathrm{M}}$. Figure $5 \mathrm{~d}$ and Figure $5 \mathrm{e}$ show the image phase contrast along the reciprocal lattice vectors $\mathbf{g}_{1}=010$ and $\mathbf{g}_{2}=102$, respectively. The dotted rectangles correspond to the regions which have been chosen for reference. The bright boxes correspond to the places in which the phase profiles in Figures $2 \mathrm{f}$ and $2 \mathrm{~g}$ have been measured. The profile of the reflexion $\mathbf{g}_{1}$ in Figure $5 f$ shows a dephasing contrast of $\Delta \varphi(\mathbf{g} 1)=-3 \mathrm{rad}$, whereas the profile of reflexion $\mathbf{g}_{2}$ in Figure $5 \mathrm{~g}$ shows a dephasing contrast of $\Delta \varphi(\mathbf{g} \mathbf{1})=1 \mathrm{rad}$. 


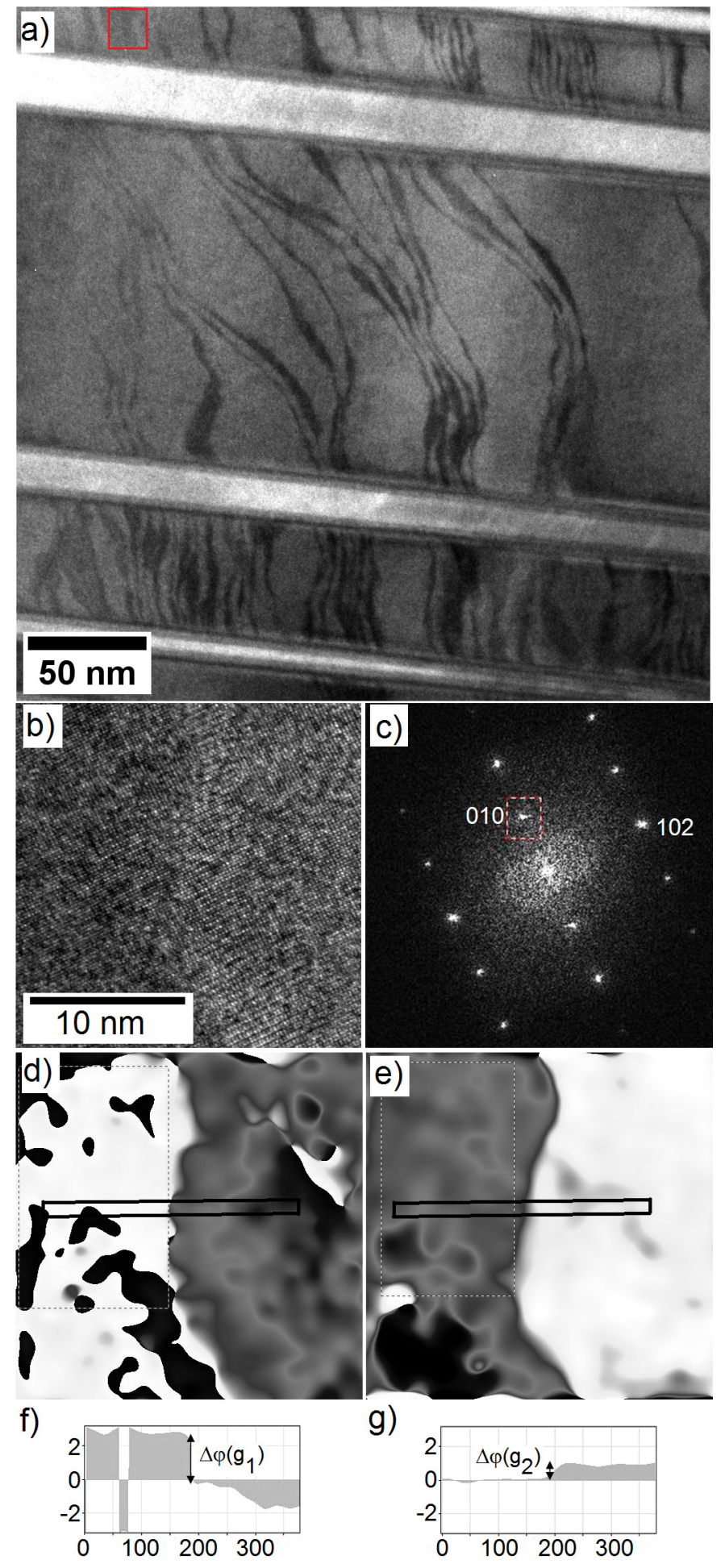

Figure 5: a) TEM BF of the Ru50Ta50 alloy, showing the region where the HRTEM is performed (red box), b) HRTEM image along the [ $20 \overline{1}$ ]M direction, c) the corresponding power spectrum, d) image phase contrast along g1 $=010, \mathrm{~d}$ ) image phase contrast along $\mathrm{g} 2=102$. The dotted rectangles correspond to the regions chosen for reference. The bright boxes correspond to the places in which the phase profiles in Figures $2 \mathrm{f}$ and $2 \mathrm{~g}$ have been measured. f) profile of the reflexion g1showing a phase change contrast of $\Delta \varphi(\mathrm{g} 1)=-3 \mathrm{rad}$ and $\mathrm{g})$ profile of the reflexion $\mathrm{g} 2$ showing a phase change contrast of $\Delta \varphi(\mathrm{g} 2)=1 \mathrm{rad}$, where $\varphi$ corresponds to the phase in question. 
This amplitude of the phase change contrast between the outside and the inside of the translation walls allows the calculation of the scalar product $2 \pi \cdot \mathbf{g} \cdot \mathbf{R}$, as will be shown subsequently.

In the case of a local strain field, the displacement of atomic planes in the real space image can be expressed by a displacement field. As the latter is linked to a family of lattice planes it is directly linked to the phase:

$P_{g}(\mathbf{r})=-2 \pi \mathbf{g} \cdot \mathbf{u}(\mathbf{r})$

where $\mathbf{r}$ is the position in space, $\mathbf{u}(\mathbf{r})$ the two-dimensional displacement field and $P_{g}(\mathbf{r})$ corresponds to the images of the local phases. It gives the position of a particular set of $\mathrm{g}$, compared to the perfect crystal which has been chosen for reference. The displacement of the atomic positions can be considered as a particular vector $g$ or as a displacement field.

By combining the information given by the two planes described by $\mathbf{g}_{1}$ and $\mathbf{g}_{2}$, the twodimensional displacement field can be written as:

$\mathrm{u}(\mathrm{r})=-1 /(2 \pi)\left[P_{g l}(\mathbf{r}) \mathbf{a}_{1}+P_{g_{2}}(\mathbf{r}) \mathbf{a}_{2}\right]$

where $\mathbf{a}_{1}$ and $\mathbf{a}_{2}$ represent the lattice in direct space, which correspond to the vectors $\mathbf{g}_{1}$ and $\mathbf{g}_{2}$ in the reciprocal lattice.

The scalar products of $\mathbf{g}_{\mathbf{1}}$ and $\mathbf{g}_{\mathbf{2}}$ can thus be calculated and become

$\mathbf{g}_{1} \cdot \mathbf{R}=3 / 2 \pi \approx 1 / 2$

$\mathbf{g}_{2} \cdot \mathbf{R}=-1 / 2 \pi \approx-1 / 6$ or $+5 / 6$

These values can now be compared to the lost translations given in Table 2 . The translation that provides these values when multiplied with $\mathbf{g}_{1}$ and $\mathbf{g}_{2}$ is $\mathrm{R}=1 / 6[132]_{\mathrm{M}}$.

The large cell of the monoclinic phase is then confirmed by the translation lost during the transformation. However, as stated before, it is clear that neither the perfectly aligned supercell in Figure 2 nor the atom positions given in Table 1 are sufficient to explain why these translations are lost when changing from the tetragonal to the monoclinic cell. In order to clarify this point, further investigations and considerations are necessary.

Beside TEM observations, general XRD experiments (not shown here) have been performed in order to gain more information about the alloys' structure. In both cases the atom positions pointed out in Table 1 have been used during the first CaRIne simulations of both X-ray diffractograms and SAD patterns. However, the simulations are not satisfying because of missing diffraction peaks or diffraction spots, respectively. The so obtained diffraction patterns can just as well be obtained by a six times smaller unit cell, which is integrated in the monoclinic unit cell (see Figure 2). In order to simulate diffraction patterns that correspond to the experimental ones it has been necessary to slightly modify the atom positions of one or more atoms in the unit cell.

This unsatisfying simulation approach as well as the considerations about the lost translations clearly points out that a correct determination of the atom position is necessary to fully understand the necessity of considering such a big unit cell.

The crystal structures of $\beta "-\mathrm{Ru}_{50} \mathrm{Nb}_{50}$ and $\beta "-\mathrm{Ru}_{50} \mathrm{Ta}_{50}$ have then been refined from the theoretical atomic positions given in Table 1. The resolution of the crystal structure has been initiated on $\beta$ "- $\mathrm{Ru}_{50} \mathrm{Ta}_{50}$ because of the high contrast between the electronic densities of the two elements. The use of Fullprof in LeBail's profile matching mode and the subsequent use of 
Patterson and Fourier syntheses allowed to approximately locate the atoms which are indeed packed in the same way as in the $\beta^{\prime}$ form. In agreement with this pseudo-C model, the peaks with odd $h+k$ appear weak, but no systematic extinction rule can be observed. This is why structural models are built in $P 2, P m$ and $P 2 / m$ space groups and refined by the Rietveld method with Fullprof. In all the cases the atoms are found to occupy the special $2 / m$ and $m$ positions of the $P 2 / m$ group. Reliability factors are very similar in all three space groups $\left(R_{\text {Bragg }}=0.030\right.$ for $P 2$, 0.030 for $P m$ and 0.032 for $P 2 / m$ ), which allows the use of $P 2 / m$ in the following. In order to reduce the number of variables in the final refinement, a common thermal factor is given to all atoms of the same species (see Table 3). The rate of Ru-Ta inversion, measured by calculating the $x$ occupancy factor in a $\left(\mathrm{Ru}_{1-\mathrm{x}} \mathrm{Ta}_{\mathrm{x}}\right)\left(\mathrm{Ru}_{\mathrm{x}} \mathrm{Ta}_{1-\mathrm{x}}\right)$ model has been found to be $3 \pm 1$, which is low enough to be neglected in the following.

\begin{tabular}{cll}
\hline$B_{\text {iso }}$ & $\mathrm{Ru}\left(\AA^{2}\right)$ & $\mathrm{Nb} / \mathrm{Ta}\left(\AA^{2}\right)$ \\
\hline$\beta^{\prime \prime}-\mathrm{Ru}_{50} \mathrm{Nb}_{50}$ & $0.2(1)$ & $0.1(1)$ \\
$\beta^{\prime \prime}-\mathrm{Ru}_{50} \mathrm{Ta}_{50}$ & $0.2(1)$ & $0.1(1)$ \\
\hline
\end{tabular}

Table 3: Measured thermal factors used for the refinement

The crystal structure of $\mathrm{Ru}_{50} \mathrm{Nb}_{50}$ has been refined starting from the atomic positions of $\beta$ ',$\mathrm{Ru}_{50} \mathrm{Ta}_{50}$. The structures were found to be isotypic with very similar cell parameters and atomic positions. The final Rietveld plot of $\beta "-\mathrm{Ru}_{50} \mathrm{Nb}_{50}$ is shown in Figure 6.

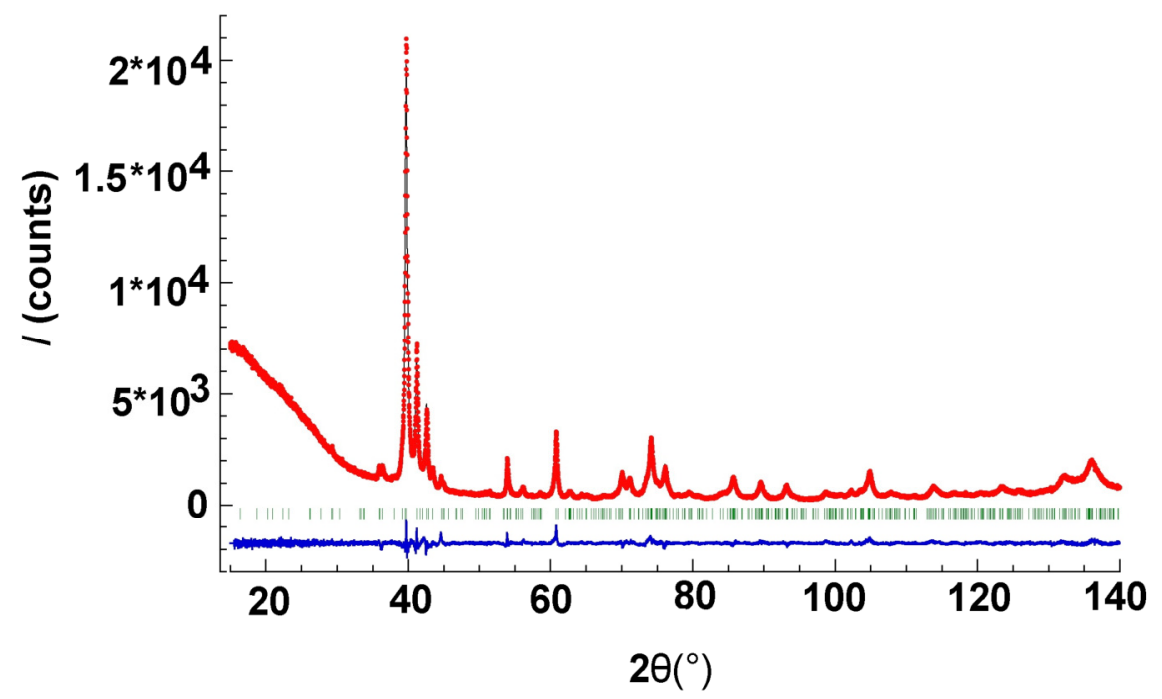

Figure 6: Final Rietveld plot for $\beta "-\mathrm{Ru}_{50} \mathrm{Nb}_{50}$. The experimental intensities are shown in red, the calculated ones in black and their difference in blue. The peak positions are given in green. 


\begin{tabular}{|c|c|c|}
\hline \multicolumn{3}{|l|}{ Refinement conditions } \\
\hline Peaks profile model & \multicolumn{2}{|l|}{ Split Pseudo-Voigt } \\
\hline I-dependent / profile parameters & $12 / 12$ & \\
\hline Alloy & $\beta "-R u N b$ & $\beta "-R u T a$ \\
\hline Observed reflections & 443 & 436 \\
\hline Conventional reliability factors & $\begin{array}{l}R_{p}=0.031 \\
R_{W P}=0.048 \\
R_{\text {Bragg }}=0.032 \\
R_{\text {exp }}=0.072 \\
X^{2}=3.0 \\
\end{array}$ & $\begin{array}{l}\mathrm{R}_{\mathrm{p}}=0.023 \\
\mathrm{R}_{\mathrm{WP}}=0.34 \\
\mathrm{R}_{\text {Bragg }}=0.034 \\
\mathrm{R}_{\text {exp }}=0.078 \\
X^{2}=2.6\end{array}$ \\
\hline \multicolumn{3}{|l|}{ Crystallographic data } \\
\hline Crystal system / space group & \multicolumn{2}{|c|}{ Monoclinic / P2/m ( $\left.\mathrm{n}^{\circ} 10\right)$} \\
\hline Cell parameters / volume & $\begin{array}{l}a=7.9943(4) \AA \\
b=4.3722(1) \AA \\
c=5.4307(3) \AA \\
\beta=96.746(3) \AA \\
V=188.50(2) \AA^{3}\end{array}$ & $\begin{array}{l}a=7.9987(3) \AA \\
b=4.3748(1) \AA \\
c=5.4192(2) \AA \\
\beta=96.636(2) \AA \\
V=188.36(2) \AA^{3}\end{array}$ \\
\hline Formula weight & $193.98 \mathrm{~g} / \mathrm{mol}$ & $282.02 \mathrm{~g} / \mathrm{mol}$ \\
\hline Atoms per unit cell & 6 & 6 \\
\hline Calculated density & $10.25 \mathrm{~g} / \mathrm{cm}^{3}$ & 14.91 \\
\hline
\end{tabular}

Table 4: Refinement conditions and crystallographic data used for the measurement of $\mathrm{Ru}_{50} \mathrm{Nb}_{50}$ and $\mathrm{Ru}_{50} \mathrm{Ta}_{50}$

The determined atom positions and the interatomic distances of the $\mathrm{Ru}, \mathrm{Nb}$ and $\mathrm{Ta}$ atoms are regrouped in Table 4 and Table 5, respectively. 


\begin{tabular}{|c|c|c|c|c|c|c|c|}
\hline \multirow[t]{2}{*}{ Atom } & \multirow[t]{2}{*}{ Site } & \multicolumn{3}{|l|}{$\beta^{\prime \prime-R u N b}$} & \multicolumn{3}{|l|}{$\beta "-R u T a$} \\
\hline & & $x$ & $y$ & $z$ & $x$ & $y$ & $z$ \\
\hline Ta1 or $\mathrm{Nb} 1$ & $1 a$ & 0 & 0 & 0 & 0 & 0 & 0 \\
\hline $\mathrm{Ta} 2$ or $\mathrm{Nb} 2$ & $1 e$ & $1 / 2$ & $1 / 2$ & 0 & $1 / 2$ & $1 / 2$ & 0 \\
\hline $\mathrm{Ta} 3$ or $\mathrm{Nb} 3$ & $2 m$ & $0.3231(5)$ & 0 & $0.639(1)$ & $0.3252(5)$ & 0 & $0.639(1)$ \\
\hline Ta4 or $\mathrm{Nb} 4$ & $2 n$ & $0.8552(5)$ & $1 / 2$ & $0.7278(8)$ & $0.8532(5)$ & $1 / 2$ & $0.7253(7)$ \\
\hline Ru1 & $1 c$ & 0 & 0 & $1 / 2$ & 0 & 0 & $1 / 2$ \\
\hline Ru2 & $1 h$ & $1 / 2$ & $1 / 2$ & $1 / 2$ & $1 / 2$ & $1 / 2$ & $1 / 2$ \\
\hline Ru3 & $2 m$ & $0.3434(5)$ & 0 & $0.144(1)$ & $0.3331(9)$ & 0 & $0.133(2)$ \\
\hline Ru4 & $2 n$ & $0.8074(5)$ & $1 / 2$ & $0.2087(8)$ & $0.8044(7)$ & $1 / 2$ & $0.201(1)$ \\
\hline
\end{tabular}

Table 5: Atomic positions for $\beta$ "-RuNb and $\beta "$ "-RuTa

\begin{tabular}{|c|c|c|c|}
\hline Ru1 & Ru2 & Nb1 & $\mathrm{Nb2}$ \\
\hline 2×Nb3 0.604(4) & $2 \times \mathrm{Nb} 22.715(1)$ & $2 \times$ Ru1 2.715(1) & $2 \times \operatorname{Ru} 42.582(4)$ \\
\hline $2 \times N b 12.715(1)$ & $4 \times N b 32.756(3)$ & $2 \times \operatorname{Ru} 32.764(4)$ & $4 \times \operatorname{Ru} 32.682(3)$ \\
\hline $4 \times N b 42.826(3)$ & $2 \times N b 4$ 2.961(4) & $4 \times N b 32.811(3)$ & $2 \times \operatorname{Ru} 22.715(1)$ \\
\hline \multirow[t]{2}{*}{ 4×Ru4 3.014(3) } & 2×Ru4 3.075(4) & 4×Ru4 2.974(3) & $4 \times N b 33.159(3)$ \\
\hline & 4×Ru3 3.085(4) & & \\
\hline Ru3 & Ru4 & Nb3 & $\mathrm{Nb} 4$ \\
\hline 2×Nb2 2.682(3) & $1 \times N b 2$ 2.582(4) & $2 \times \operatorname{Ru} 42.600(4)$ & $1 \times \operatorname{Ru} 42.679(6)$ \\
\hline $1 \times N b 32.709(8)$ & $2 \times N b 32.600(4)$ & $1 \times \operatorname{Ru} 12.604(4)$ & $1 \times \operatorname{Ru} 42.682(6)$ \\
\hline $1 \times N b 32.732(8)$ & $1 \times N b 42.679(6)$ & $2 \times$ Ru2 $2.756(3)$ & $1 \times \operatorname{Ru} 42.802(6)$ \\
\hline $1 \times \mathrm{Nb} 12.764(4)$ & $1 \times N b 4$ 2.682(6) & $1 \times$ Ru3 $2.709(8)$ & $2 \times \mathrm{Nb} 12.811(3)$ \\
\hline $1 \times N b 32.787(6)$ & $1 \times N b 4$ 2.802(6) & $1 \times$ Ru3 $2.732(8)$ & $2 \times \operatorname{Ru} 12.826(3)$ \\
\hline 2×Nb4 2.835(4) & 2×Nb1 2.974(3) & $1 \times \operatorname{Ru} 32.787(6)$ & $2 \times \operatorname{Ru} 32.835(4)$ \\
\hline 2×Ru4 3.059(4) & 2×Ru1 3.014(3) & $2 \times \mathrm{Nb} 23.159(3)$ & $1 \times$ Ru2 2.961(4) \\
\hline 2×Ru2 3.085(3) & 2×Ru3 3.059(4) & $2 \times N b 43.179(5)$ & $2 \times N b 33.179(5)$ \\
\hline $1 \times \operatorname{Ru3} 3.106(7)$ & $1 \times$ Ru2 $3.075(4)$ & & \\
\hline
\end{tabular}

Refinement conditions and crystallographic data used for the measurement of $\mathrm{Ru}_{50} \mathrm{Nb}_{50}$ and $\mathrm{Ru}_{50} \mathrm{Ta}_{50}$ are summarized in Table 4.

The Ru1-2 and Ta/Nb1-2 remain in the same position in $\beta^{\prime \prime}$ as they occupied in the $\beta^{\prime}$ form, and they remain coplanar. A moderate shift can be observed for Ru3 (0.156(5) $\AA$ ) and Nb3 (0.164(5) $\AA)$ and a strong one for Ru4 $(0.550(6) \AA)$ and Nb4 (0.355(4) $\AA)$. This results in zig-zag rows following the $[1,-3,2]_{\beta}$ direction, as shown in Figure 7 . However, considering the isoatomic $(-2$, $0,1)_{\beta "}$ planes, which correspond to the former $(0,0,1)_{\beta}$ planes, it appears that the Ru3-4 atoms shift along the plane, whereas $\mathrm{Nb} / \mathrm{Ta} 3-4$ shift perpendicularly to the plane. Thus the Ru surfaces remain nearly flat, whereas the $\mathrm{Nb} / \mathrm{Ta}$ surfaces become strongly corrugated (see Figure 8), which results in a mean $\mathrm{Ru}-\mathrm{Ru}$ distance $(3.22 \AA$ in $\beta "-\mathrm{RuNb})$ that is shorter than the mean $\mathrm{Nb}-\mathrm{Nb}$ distance $(3.27 \AA)$. This is in agreement with the difference in atomic radii.

The monoclinic distortion seems thus to relax the local strains resulting from the difference in atomic radii between the two elements. The distortion of the two sublattices also seems correlated, as the protruding Nb4 atom pushes aside the Ru3-4 atoms as shown in Figure 8. 

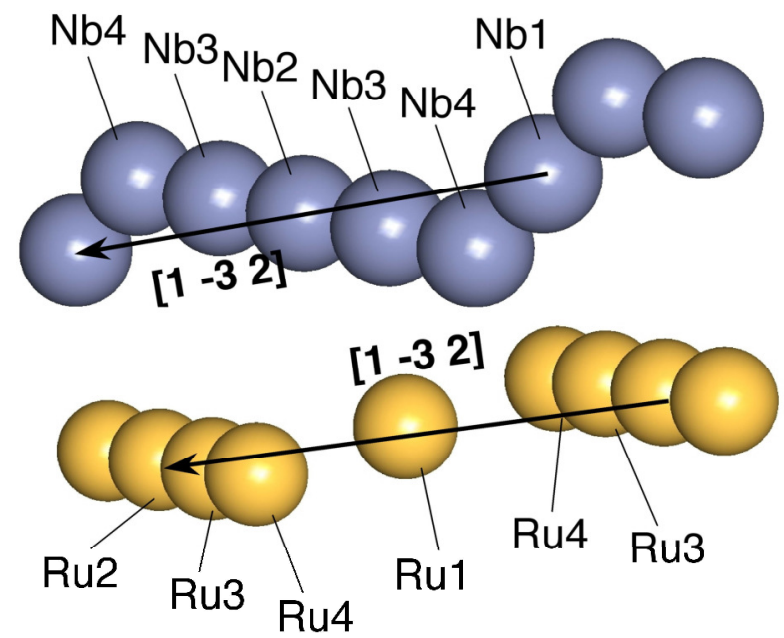

Figure 7: Zigzaging atomic chains along the $[1,-3,2]_{\beta "}$ axis in $\beta^{\prime \prime}-\mathrm{RuNb}$, showing the shifts of the Ru3-4 and Nb3-4 atoms away from the axis.

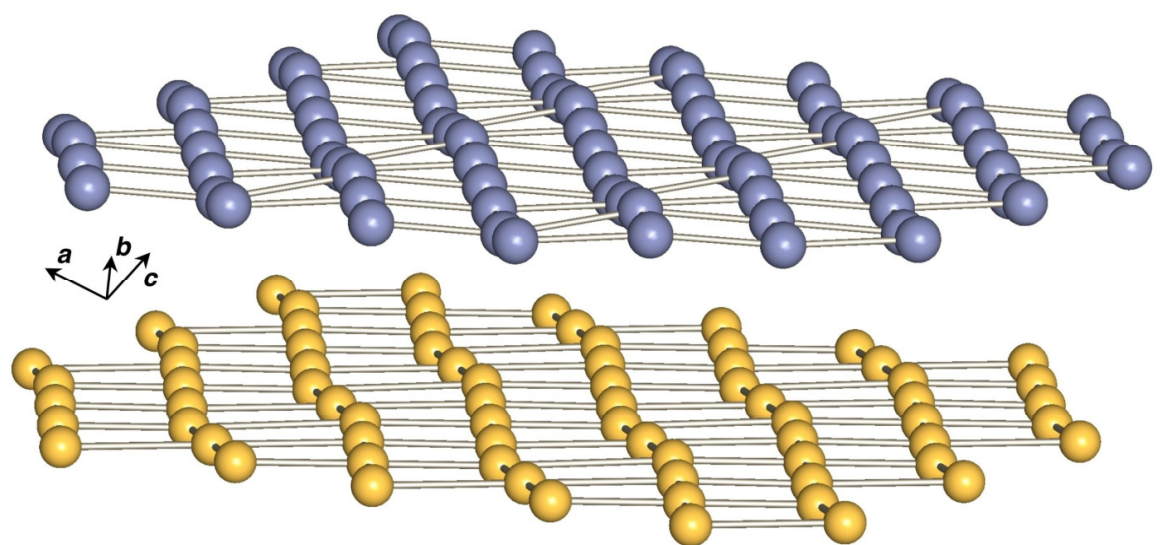

Figure 8: Isoatomic surfaces $\left((-2,0,1)_{\beta "}\right.$ planes $)$ in $\beta "-R u N b$. Blue: $\mathrm{Nb}$ atoms, yellow: Ru atoms

In a would-be room-temperature $\beta$-RuNb form with the same cell volume, every atom should have eight neighbours of the other element at $2.773 \AA$ and six of the same element at $3.155 \AA$. Table 5 shows marked variations of these distances and, for most of the $\mathrm{Nb}$ atoms, a perturbation in the order with atoms of the same species among the eight closest neighbours. This change of environment results probably from the shift of the atoms out of their medium plane.

The observation of the atoms' shifts and the resulting waviness of the planes also confirm the fact that this phase is not an $\omega$ phase, even though there are some similarities, as has been suggested by Fonda and Vandermeer [8].

\section{$\underline{\text { Summary }}$}

TEM observations of the smallest scale twins in equiatomic RuTa and RuNb show a wavy contrast, which can be explained by the loss of translational symmetry during the phase transformation from the tetragonal $\beta^{\prime}$ martensite to the monoclinic $\beta^{\prime \prime}$ martensite. The six times bigger monoclinic cell is characterized by the disappearance of five translations. An investigation of the structure by X-ray diffraction and Rietveld analysis reveals the fact that the isoatomic surfaces in the structure, which have been expected to be flat, are actually periodically wavy along the former cubic $[100]_{C}$ direction in the former cubic (100) planes. 


\section{$\underline{\text { Acknowledgement }}$}

The authors would like to thank A. Bachelier-Locq and C. Ramusat for help with sample preparation and C. Sanchez for help with X-ray diffraction experiments. The authors thank the French Foundation of Research for Aeronautics and Space (FRAE) for its support in the AMFORTAS project. Many thanks to D. Többens (Helmholtz-Zentrum Berlin) for most valuable discussion and help with visualization of structures.

\section{Data availability}

The raw/processed data required to reproduce these findings cannot be shared at this time due to technical or time limitations.

\section{$\underline{\text { References }}$}

[1] K. Otsuka, X. Ren, Recent developments in the research of shape memory alloys, Intermetallics, 7 (1999) 511-528.

[2] J. Ma, I. Karaman, R.D. Noebe, High temperature shape memory alloys, Int. Mat. Rev., 55 (2010) 257-315.

[3] R.W. Fonda, H.N. Jones, R.A. Vandermeer, The shape memory effect in equiatomic TaRu and NbRu alloys, Scripta Mater., 39 (1998) 1031-1037.

[4] R.W. Fonda, H.N. Jones, R.A. Vandermeer, The shape memory effect in ruthenium alloys, Minerals Metals \& Materials Soc, Warrendale, 1999.

[5] P. Vermaut, A. Manzoni, A. Denquin, F. Prima, R.A. Portier, Unexpected Constrained Twin Hierarchy in Equiatomic Ru-based High Temperature Shape Memory Alloy Martensite, in: S. Prokoshkin, N. Resnina (Eds.) European Symposium on Martensitic Transformations, 2013, pp. 195-199.

[6] A. Manzoni, Alliages à mémoire de forme hautes températures base Ru pour application turbomachines, Université Pierre et Marie Curie, Paris, France, 2011.

[7] K. Chastaing, Etude d'alliages à mémoire de forme base Ru pour applications hautes températures, Université Pierre et Marie Curie, Paris, France, 2007.

[8] R.W. Fonda, R.A. Vandermeer, Crystallography and microstructure of TaRu, Phil. Mag. A, 76 (1997) 119-133.

[9] A.M. Manzoni, A. Denquin, P. Vermaut, F. Prima, I. Puente-Orench, C. Pauly, F. Mücklich, R.A. Portier, Constrained hierarchical twinning in Ru-based high temperature shape memory alloys, Acta Materialia, 111 (2016) 283-296.

[10] K. Chastaing, A. Denquin, R. Portier, P. Vermaut, High-temperature shape memory alloys based on the RuNb system, Mat. Sci. Eng. A, 481 (2008) 702-706.

[11] A. Manzoni, K. Chastaing, A. Denquin, P. Vermaut, R. Portier, Shape recovery in high temperature shape memory alloys based on the $\mathrm{Ru}-\mathrm{Nb}$ and $\mathrm{Ru}-\mathrm{Ta}$ systems, in: P. Sittner, V. Paidar, L. Heller, H. Seiner (Eds.) Esomat 2009 - 8th European Symposium on Martensitic Transformations, Prague, Czech republic, 2009.

[12] B.K. Das, M.A. Schmerling, D.S. Lieberman, Some aspects of phase transformations in near-equiatomic niobium-ruthenium alloys, Materials Science and Engineering, 6 (1970) 248254. 
[13] S.M. Shapiro, G. Xu, G. Gu, J. Gardner, R.W. Fonda, Lattice dynamics of the hightemperature shape-memory alloy Nb-Ru, Physical Review B, 73 (2006) 214114.

[14] B.H. Chen, H.F. Franzen, High temperature X-ray diffraction and Landau theory investigation of phase transitions in NbRu1 $+x$ and RhTi, J. Less. Common Met., 153 (1989) L13-L19.

[15] R.W. Fonda, H.N. Jones, Microstructure, crystallography, and shape memory effect in equiatomic NbRu, Mat. Sci. Eng. A, 273 (1999) 275-279.

[16] A. Boultif, D. Louer, Indexing of powder diffraction patterns for low-symmetry lattices by the successive dichotomy method, Journal of Applied Crystallography, 24 (1991) 987-993.

[17] J. Rodriguez-Carvajal, Recent advances in magnetic structure determination by neutron powder diffraction, Physica B, 192 (1993) 55-69.

[18] C. Boudias, M. Monceau, CaRIne Crystallography Software, 1989-2005.

[19] M.J. Hytch, E. Snoeck, R. Kilaas, Quantitative measurement of displacement and strain fields from HREM micrographs, Ultramicroscopy, 74 (1998) 131-146. 